Analysis

\title{
The Influence of Political Orientation on the Strength and Temporal Persistence of Policy Framing Effects
}

\author{
Samdruk Dharshing, Stefanie Lena Hille *, Rolf Wüstenhagen * \\ University of St. Gallen, IWOE-HSG, Tigerbergstr. 2, 9000 St. Gallen, Switzerland
}

\section{A R T I C L E I N F O}

\section{Article history:}

Received 22 May 2016

Received in revised form 17 April 2017

Accepted 7 May 2017

Available online $\mathrm{xxxx}$

\begin{abstract}
A B S T R A C T
The objective of this research is to analyze how political orientation moderates the influence of framing effects on policy evaluation. Drawing on the theory of motivated reasoning, three interrelated experiments assess the strength and temporal persistence of framing effects in the context of an energy conservation program. In the first experiment $(\mathrm{N}=183$ ), the delivery mechanism of the policy is described as either a tax rebate or a subsidy. Party identification of potential beneficiaries moderates the existence and magnitude of framing effects. The second experiment $(\mathrm{N}=603)$ presents alternative frames of communication, which focus on either the economic or environmental benefits associated with the policy. Effects of the communication frames on policy support in comparison to a neutral text are significant, but only when the policy is consistent with respondents' pre-existing views on economic individualism and government spending. The third experiment $(\mathrm{N}=603)$ investigates the temporal stability of framing effects after cognitive deliberation and finds that no change in policy support occurs over time. A key implication is that tailoring frames to the target audience increases effectiveness in policy design and communication. Considering the persistence of framing effects, early frames may have a disproportionate impact in public discourse.
\end{abstract}

(C) 2017 Elsevier B.V. All rights reserved.
"How can even sincere democratic representatives respond correctly to public opinion when empirical evidence of it appears to be so malleable, so vulnerable to framing effects?"

[Entman (1993, p. 57).]

\section{Introduction}

Behavioral research indicates that arbitrary differences in contextual information can lead to preference changes in otherwise identical choice tasks (Tversky and Kahneman, 1986), contrary to the principle of 'invariance' proposed by Neumann and Morgenstern (1947). These empirical observations have given rise to the concepts of 'framing' and 'framing effects' which are defined as "subtle alterations in the statement or presentation of judgment and choice problems and [...] changes in decision outcomes resulting from these alterations" (Iyengar, 1994, p. 11). Building on the pioneering work of Tversky and Kahneman (1981), a large body of research in psychology and behavioral economics has advanced the knowledge base on framing and devel-

\footnotetext{
* Corresponding authors.

E-mail addresses: samdruk.dharshing@unisg.ch (S. Dharshing), stefanie.hille@unisg.ch (S.L. Hille), rolf.wuestenhagen@unisg.ch (R. Wüstenhagen).
}

oped typologies of different framing effects (Levin et al., 2002; Levin et al., 1998). A parallel stream of literature in policy research, most notably driven by Druckman (2001), has applied insights from framing theory in the fields of policy design (e.g. Madrian, 2014) and policy implementation, particularly regarding the communication of policy measures (Chong and Druckman, 2007a; Klar et al., 2013).

Consistent with literature on individual differences (e.g. LeBoeuf and Shafir, 2003; Smith and Levin, 1996), policy researchers have shown that the strength of framing effects depends on various moderating factors; in particular political orientation (Chong and Druckman, 2012; Faricy and Ellis, 2014). The concept of political orientation is typically structured along a uni-dimensional model from liberal to conservative or from right-wing to left-wing (Jost et al., 2003), or along a two-dimensional model encompassing a social and an economic dimension (e.g. Duckitt, 2001; Feldman and Johnston, 2014; Jost et al., 2009; Zumbrunnen and Gangl, 2008). Despite an increasing amount of research on the impact of political orientation on policy framing effects, empirical evidence in the field of environmental policy, while growing, is still in its early stages. This research gap seems surprising, given that the influence of political orientation could be particularly relevant to framing effects related to environmental policy instruments, which are often subject to ideological public discourses (Bornstein and Lanz, 2008; Söderbaum, 1999). Drawing on the theory of motivated 
reasoning (Slothuus and De Vreese, 2010; Taber et al., 2009; Taber et al., 2001), this paper contributes to the few existing studies (e.g. Hardisty et al., 2010) by analyzing whether the impact of frames in both policy design and communication is contingent on political orientation. To the authors' knowledge, this paper ranks among the first analyses of the influence of political orientation on framing effects in environmental policy.

In addition, this paper makes a contribution to existing literature by analyzing how political orientation influences the stability of framing effects over time. Despite some pioneering longitudinal studies on framing effects (Druckman et al., 2012), research on the influence of political orientation on the stability of framing effects in the field of environmental policy is scant. Given that many environmental policy programs require political commitments over longer time horizons, it is important to understand the temporal dynamics of policy evaluation.

The empirical part of this paper consists of three independent but closely related experiments in the context of a residential energy conservation program. In contrast to many previous studies in the field of policy framing effects that rely on student samples (e.g. Faricy and Ellis, 2014), the experiments described herein strive to create a more realistic choice setting. To do so, both potential beneficiaries of a specific policy measure and a broader population are surveyed, given that policies need not only to be favorably evaluated by the general population but also to be effective at influencing potential beneficiaries to favor their uptake.

In the first experiment, the delivery mechanism for a government benefit for an energy conservation measure is described as either a 'tax rebate' or a 'subsidy'. The experiment analyzes how political orientation moderates the impact of the framing of the delivery mechanism on the perceived importance of the benefit among potential beneficiaries. In the second experiment, the frames of a policy program for energy conservation measures highlight either economic or environmental aspects of the policy. The experiment analyzes how citizens' political orientation moderates the impact of each of the frames on their policy evaluations. The third experiment investigates whether the framing effect induced by the second experiment diminishes after reasoning about government spending and, if so, whether political orientation influences the degree of change in opinion over time.

Overall, this paper contributes to knowledge about an important issue in environmental policy: the built environment, which includes residential, industrial and commercial buildings, is responsible for approximately $40 \%$ of total global energy consumption and $30 \%$ of global greenhouse gas emissions (Sbci, 2009). Given the environmental impact of energy consumption, reducing the energy demand of buildings is one of the key objectives in contemporary environmental policy (BFE, 2013b). To increase the effectiveness of the communication of sustainable energy policy, it is important to understand whether and how people react (a) to different delivery mechanisms of a government benefit and (b) to different communication frames. The findings of this study can help policy makers design better 'tailored' messages, similar to customer segmentation strategies in business and marketing.

\section{Theory and Hypotheses}

\subsection{Political Orientation and Framing Effects}

To understand how political orientation moderates the impact of framing effects on policy evaluation, the theory of 'motivated reasoning' provides a helpful framework. According to Kunda (1990), the basic premise of 'motivated reasoning' claims that individuals are subject to selective information processing, which drives them to reach conclusions that defend their preconceptions. Researchers suggest a close relationship between 'motivated reasoning' and political opinion formation (Taber et al., 2009; Taber and Lodge, 2006; Taber et al., 2001), demonstrating that citizens interpret policy-related information in a way that is consistent with the dominant beliefs of their ideological affinity group (Kahan, 2013). A closely related stream of literature suggests that motivated reasoning can lead to belief polarization, a process by which individuals with diverging prior beliefs update their opinions in opposite directions when presented with the same information (Cook and Lewandowsky, 2016). Some pioneering studies demonstrate an interplay between the mechanisms of motivated reasoning and framing effects; in particular, frames on politically contentious issues can activate political predispositions and thus induce individuals to interpret messages from the perspective of their pre-existing political beliefs (e.g. Hart and Nisbet, 2012; Slothuus and De Vreese, 2010). Extending these studies, the current work assesses how political orientation moderates the influence of framing effects on policy evaluations among both potential beneficiaries and the public. In particular, the authors analyze how frames related to the policy delivery mechanism influence policy uptake in the former and how communication frames affect policy support in the latter.

\subsubsection{Framing of Policy Delivery Mechanism}

To reduce energy consumption and its adverse environmental impacts, many countries have introduced different policy support measures such as direct payments or tax rebates for building owners who engage in energy conservation (International Energy Agency, 2013). Research suggests that the perception of such policy benefits among potential recipients is contingent on the description of their delivery mechanisms (Epley and Gneezy, 2007; Epley et al., 2006; Faricy and Ellis, 2014). Epley et al. (2006), for instance, show that a tax rebate framed as 'bonus income' is more likely to be spent than 'withheld income', because the former is perceived as a gain in wealth while the latter is considered a returned loss. Based on the utility function proposed by Kahneman and Tversky (1979), they suggest that recipients evaluate a benefit comparatively rather than absolutely, and thus changes to the status quo are perceived as either gains or losses against a given reference point. Similarly, Lozza et al. (2010) show that not only the likelihood of saving but also the perceived importance of a fiscal bonus is significantly lower when the benefit is framed as a 'bonus' (gain) rather than a 'tax rebate' (loss reduction).

While these prior studies have analyzed only the average framing effect, the theory of motivated reasoning raises the question whether the perception of frames related to policy delivery mechanisms depends on citizens' political orientation. Hardisty et al. (2010), for example, find that using the label 'tax' instead of 'offset' for a carbon dioxide surcharge significantly alters how favorably the surcharge is perceived among Republicans, but not Democrats. In a similar vein, the current paper argues that affiliates of tax-averse political parties acting as 'motivated reasoners' attach higher subjective value to a benefit framed as a 'tax rebate' rather than a 'subsidy'. In contrast, we expect that the benefit frame will not make any difference for affiliates of other parties. This hypothesis is based on prior policy research that shows that right-wing political parties are more skeptical of direct public spending but hold more favorable attitudes toward tax rebates than left-wing parties (Faricy and Ellis, 2014).

H1. The party identification of policy beneficiaries moderates the impact of framing on the perceived importance of a government benefit.

\subsubsection{Framing in Policy Communication}

'Frames in communication', which refer to a particular perspective highlighted by a speaker (e.g. a politician), play a crucial role in public discourse and can influence support for policies (Chong and Druckman, 2007b). While the conventional communication frame in the area of environmental policy focuses mainly on environmental benefits, other possible communication frames include economic considerations (Scrase and Ockwell, 2010) and health benefits (Bernauer and McGrath, 2016). Bernauer and McGrath (2016) find that shifting communication frames for climate change policy from environmental to 
alternative considerations does not significantly change support for climate policy, whereas other authors suggest that the effect depends on the frame recipients' political orientation. Lockwood (2011), for example, finds that conservative voters in the UK react less favorably to energy efficiency policy than affiliates of other political groups if the communication frame focuses on addressing the historical responsibility for addressing climate change. Using simulated news stories, Hart and Nisbet (2012) find that readers' political partisanship moderates the influence of social distance cues on identification with victims of climate change, which leads to a 'boomerang' effect among Republicans. Petrovic et al. (2014) show that a communication frame centered on health benefits is more likely to induce attitude change among US conservatives than a frame focused on climate change and that the opposite effect occurs among liberals.

Building on these studies, the current paper assesses how political orientation moderates the impact of two communication frames - one focused on environmental benefits and the other on economic benefits - on public support for an energy conservation program. This research focuses on the economic dimension of political orientation, in particular citizens' endorsement of free market liberalism, which is characterized by the concept of economic individualism and markets with minimal government intervention (Heywood, 2012). The rationale for centering on the concept of market liberalism is grounded in prior research demonstrating a potential ideological conflict between endorsement of free markets and environmental policy instruments, which often require active government intervention (Bell, 2002; De-Shalit, 1995; Heath and Gifford, 2006; Kahan, 2010). Drawing on the theory of motivated reasoning, we argue that support for a policy will increase among supporters of free market liberalism when the communication frame shifts from environmental to economic benefits, which resonate more strongly with their pre-existing ideology. In contrast, we expect that the communication frame will not make any difference for supporters of economic interventionism, given that environmental policy instruments are not per se inconsistent with their political identification group.

H2. Support for free market liberalism moderates the influence of a frame in communication on public support for environmental policy.

\subsection{Temporal Dynamics of Framing Effects}

While most empirical research has focused on examining framing effects at a single point, a question of practical relevance is whether the effects of communication frames persist over time. Changes in public opinion that occur under mixed, often controversial discourse are particularly relevant for environmental policy, given that the related challenges are inherently characterized by a focus on long-term development and inter-generational justice (Klauer et al., 2013). Two separate but interlinked considerations are relevant for understanding the temporal dynamics of framing effects. First, the impact of framing effects is generally expected to decay over time (Chong and Druckman, 2010; De Vreese,
2004; Gerber et al., 2007; Tewksbury et al., 2000). Second, as the impact of earlier communication frames fades, subsequent messages may influence opinion formation because of the recency effect; that is, the latest available information may be awarded a disproportionate amount of weight (Chong and Druckman, 2010). In this context, Chong and Druckman (2012, p. 2) define a counter-frame as "a frame that opposes an earlier effective frame" and demonstrate that the decay rate of the initial frame after the presentation of a counter-frame varies, depending on the recipient's mode of information processing and attitude strength. However, in contrast to the 'captive' situation of a lab experiment, in which participants are only exposed to specific frames and counterframes, most citizens engage in informal information searches or discussions with family, friends and other peers before forming their opinions (Walsh, 2004). In this regard, Druckman and Nelson (2003) find that participation in a mixed discussion, in which the other discussion participants have previously been exposed to a different frame, reverses the initial bias induced by a 'framed' article. In contrast, engaging in an 'unmixed' discussion (with individuals who have been exposed to the same frame) has no moderating influence on the framing effect.

Extending prior literature, we again draw on the theory of motivated reasoning to analyze whether the respondents' political orientation moderates the impact of mixed arguments on the decay of the initial frame. Druckman et al. (2012), for instance, show that framing effects persist over time when respondents are allowed to select subsequent information themselves and thus engage in directional information search caused by motivated reasoning. Depending on whether an initial frame on energy conservation expenditure is consistent with the respondents' support for free market liberalism, we expect that a mixed discussion about government spending will lead to either reinforcement or reversal of the framing effect. Exposing citizens to a mixed discussion with different ideological viewpoints may motivate them to update their opinions in a way that is more closely aligned with their original beliefs. We therefore hypothesize:

H3. The political orientation of beneficiaries influences the degree of preference change that occurs after cognitive deliberation about government expenditure.

\section{Overview of Experiments}

We conducted three online experiments which analyzed the impact of political orientation on framing effects related to environmental policy. Experiment 1 analyzed how party identification moderates the change in the perceived importance of a government benefit for energy saving home improvements when it is framed as a 'tax rebate' instead of a 'subsidy'. The first experiment investigated the impact of policy framing effects from the perspective of homeowners as potential beneficiaries of the government benefit in question. Experiment 2 analyzed whether support for free market liberalism moderates the influence of a frame in communication on policy evaluation for a government

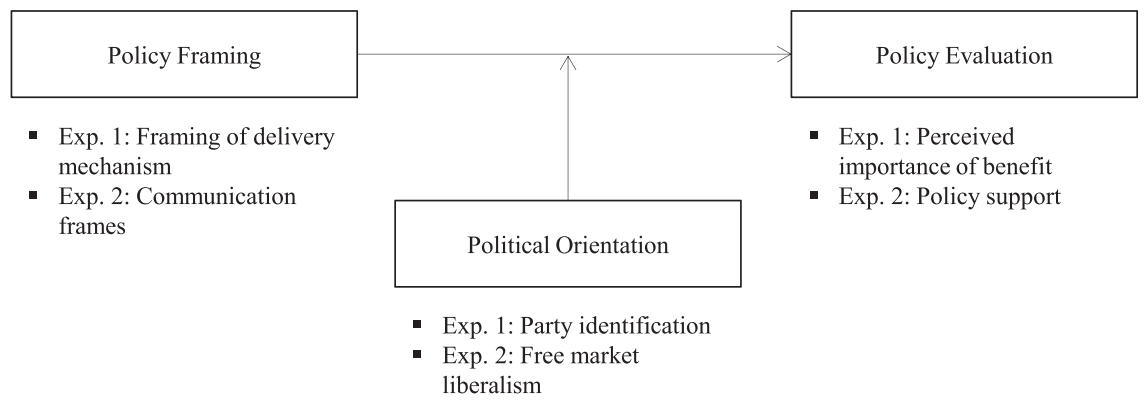

Fig. 1. Overview of dependent, independent and moderating variables in Experiments 1 and 2. 
program targeted at residential energy conservation. Fig. 1 graphically displays the models tested in experiments 1 and 2. Following this, experiment 3 investigated if cognitive deliberation about government spending after reading a 'framed' text reverses the original framing effect, and if so, whether the degree of preference change depends on political orientation. Data for the second and third experiment were drawn from the general Swiss population to facilitate the analysis of policy evaluation among the population (i.e. both beneficiaries and non-beneficiaries of the government benefit).

\subsection{Experiment 1}

The first experiment investigated the influence of party identification on the perception of changes in the labeling of a government benefit's delivery mechanism. For the purpose of eliciting the preferences of beneficiaries, we put significant effort into creating a neutral decision environment which did not solely focus on government benefits or political orientation. Previous research has shown that direct questions about (politically) sensitive issues can lead respondents to mask their true preferences and provide socially desirable answers (Fisher, 1993). For this reason, we conducted a choice-based conjoint (CBC) experiment, which is an indirect way of eliciting preferences (Heinzle and Wüstenhagen, 2012).

\subsubsection{Methodology and Experimental Procedure}

3.1.1.1. Object of Investigation. Many countries such as Switzerland have implemented government-sponsored benefit schemes to promote the uptake of residential energy conservation and efficiency measures. In Switzerland, both tax rebates and direct subsidies are offered to homeowners in several cantons (regions) to incentivize energy saving home improvements (BFE, 2013a). All participants were told that the main objective of the study was to elicit their opinions about residential energy efficiency retrofits (which are eligible for government support).

3.1.1.2. Experimental Design. Choice experiments are an indirect method of eliciting individual preferences by observing participants' choices during a number of choice tasks in which they are forced to make trade-offs between different attributes (Green and Srinivasan, 1990). We created two experimental designs, which were exactly identical except for how government benefits were labeled. All participants were randomly sorted into an experimental group using a computer-based selection system. The key manipulation was that in one experimental group the government support scheme was labeled a 'subsidy', while in the other group it was framed as 'tax rebate'. This allowed us to trace back the different preferences of the groups to the manipulated framing of the government benefit.

The attribute 'investment cost', which was either $55,000,70,000$ or 85,000 Swiss Francs $\left(\mathrm{CHF}^{1}\right)$, encompassed the upfront costs of conducting a home retrofit project. The attribute 'government support' was either labeled a 'subsidy or a 'tax rebate'; however, the absolute values were the same in both groups $(5,000,10,000$ or $15,000 \mathrm{CHF})$. The attribute 'energy cost savings' described the expected annual energy cost saving, which was defined as $1,000,1,500$ or 2,000 CHF per year. The last attribute was the increase in 'thermal comfort' after the home renovation. This was included as a dichotomous attribute with only two levels (slight increase vs. significant increase in thermal comfort).

In each choice task the participant was presented with three different home renovation projects ('concepts'), each having a combination of four different attribute levels. The $\mathrm{CBC}$ included a total of 13 choice tasks with three concepts each in a row, for a total of 39 concepts. For each choice task, the participant was asked to choose their preferred option among the three concepts.

\footnotetext{
1 One CHF corresponds to 1.008 USD as of March 28, 2017.
}

The fractional factorial design applied in this choice experiment followed the 'complete enumeration' method. This strategy seeks to achieve orthogonality between attribute levels, balanced frequency in the display of each attribute level and minimal overlap; i.e., duplicate levels within choice sets are avoided (Chrzan and Orme, 2000).

\subsubsection{Measures}

3.1.2.1. Importance Score of the Government Benefit. The dependent variable of this between-subject analysis was the importance score of the government benefit, which was derived indirectly from the decisions made in the choice experiment. This score shows how much weight the participant attached to the government benefit as a decision criterion when they were asked to choose between different renovation projects. Therefore, this variable measures to what extent homeowners base their decisions on policy incentives relative to the other (financial and non-financial) attributes of the home renovation project. It can thus be interpreted as a proxy for policy effectiveness in the sense that the policy incentives would be perceived as important decision criterion by the targeted beneficiaries. The importance scores of all experimental attributes were estimated using the Hierarchical Bayes (HB) method. The key methodological advantage of HB over aggregate models (such as multinomial logit analysis) is that it allows the researcher to assess preferences based on individual-level choice data (for a more detailed review of the HB method, see e.g. Rossi and Allenby, 2003).

3.1.2.2. Political Orientation. Respondents were asked to state which political party they belong to or vote for. In contrast to the two-party system in the USA, Switzerland has a wide range of different parties. For this study, the parties were classified according to their positioning related to economic issues or free market liberalism based on the leftright-classification of Bochsler et al. (2015). ${ }^{2}$ Similar to the situation in the USA, parties on the economic right in Switzerland stand for "privatization, lower taxes, less regulation, and a leaner welfare state" (Bochsler et al., 2015, p. 477). In order to obtain a clear-cut division between left and right, only the clearest and least controversial examples of left- and right-wing parties were included in the analysis. ${ }^{3}$ The Green Party (GPS), as well as the Social Democratic Party (SPS), were identified as the main left-wing parties in Switzerland. The Swiss People's Party (SVP), the Swiss Federal Democratic Union (EDU), the Civic Democratic Party (BDP) and the Liberal Democratic Party (FDP) were identified as right-wing parties. ${ }^{4}$

3.1.2.3. Time Preference. Some government benefits, such as tax rebates, are often not paid out immediately, but only at the end of the taxation period. Accordingly, we controlled for the influence of time preferences. The method applied in this study was a 'to wait or not' binary choice task based on the approach developed by Frederick (2005). Respondents could choose between receiving a certain amount of money now, or a greater amount at a later time. The aim was not to identify the discount rate but rather to discriminate between more and less patient respondents, similar to an 'adult version' of the Marshmallow Test (Burks et al., 2012). The number of 'impatient' choices was summed to form an impatience scale (see Appendix A).

\footnotetext{
2 The term 'liberalism' used in Switzerland is not completely equivalent to the concept of 'liberals' (vs. 'conservatives') which exists in the United States. In the Swiss context, 'liberalism' could either refer to social or free market liberalism. While the former is mainly associated with left-wing parties, the latter is more strongly attributed to right-wing parties (Bochsler et al., 2015).

${ }^{3}$ Two centrist parties were not considered in this part of the analysis: According to Bochsler et al. (2015), the Green Liberal Party (GLP) holds 'center-right' opinions on economic issues. However, it is congruent with the left-wing Green Party on environmental topics. Similarly, the Christian Democratic Party (CVP) switches between center-right and center-left positions depending on the topic in question.

${ }^{4}$ Shares of votes in the 2015 national parliamentary elections: GPS 7.1\%, SPS $18.8 \%$, SVP 29.4\%, EDU 1.2\%, BDP 4.1\%, FDP 16.4\% (http://www.politik-stat.ch/, retrieved March 31 2017).
} 
3.1.2.4. Risk Preference. Future rewards are typically associated with a certain degree of uncertainty (e.g. unexpected political events may prevent the payment of a government benefit). Similarly to the methodology applied by Donkers et al. (2001), risk preference was elicited by three different lotteries, each of which had two different outcomes with given probabilities of 'winning'. Respondents were asked to choose their preferred lottery, and the amount of risky choices were summed to create a risk attitude scale. A pre-test with 30 participants found high levels of risk aversion, so the original questions of Donkers et al. (2001) were slightly modified in order to make the risky option slightly more attractive. Although the questions were hypothetical, a number of previous studies have shown that the absence of incentives does not make a difference in simple, pairwise choice tasks (e.g. Beattie and Loomes, 1997; Camerer and Hogarth, 1999; Donkers et al., 2001).

3.1.2.5. Numeracy. As the choice experiment involved a comparison of different costs, we also controlled for the numerical abilities of individuals using three standard tasks from literature about financial literacy and numeracy (Lusardi and Mitchell, 2011). Respondents received one point for each correct answer, which were added to create a numeracy scale. The exact wording of all items can be found in the Appendix A to this paper.

3.1.2.6. Environmental Friendliness. Energy-saving measures of residential households not only save money but also reduce the adverse environmental impacts created by energy consumption. Therefore, respondents were asked to self-report their level of environmentalfriendliness on a 5-point Likert scale (ranging from $1=$ Not environmentally-friendly at all to $5=$ Very environmentally-friendly).

3.1.2.7. Other Covariates. This study controlled for factors related to socioeconomic status (namely, income and education), as well as respondents' gender and age. Since the study focused on examining government incentives for home renovation, we controlled for building age, owner-occupancy and type of heating system.

\subsubsection{Sampling and Data Quality}

3.1.3.1. Sampling Procedure. Data was collected through Intervista, a professional Swiss market research firm which contacted homeowners registered in their database by email. The research firm drew their respondents from a total panel of over 50,000 citizens, which constitutes one of the most extensive market research databases in Switzerland. ${ }^{5}$ The key sampling requirement was that the individual should own at least one house in Switzerland. Given that home retrofits are associated with significant cost, respondents' potential lack of financial resources was a concern which could have rendered the decision setting of the experiment less realistic. In order to mitigate this issue, we implemented a screening question which asked respondents whether they could imagine undertaking a major home renovation project within the next 10 years. When respondents replied that they would absolutely not take on such a renovation project, they were screened out.

3.1.3.2. Data Quality Assurance. Participants were remunerated by Intervista for completing surveys with 'credit points' that may be spent in designated online shops. In order to reduce the adverse effects of incentive payments, we embedded a simple attention check into our survey. ${ }^{6}$ Inattentive participants who selected the wrong answer to this question were screened out.

\footnotetext{
${ }^{5}$ https://www.intervista.ch/en/panel.

6 The attention question was as follows: "This is a little test to check whether you are paying attention. Please select the word 'energy' from the following list." Respondents were given a list of four items to choose from, including 'politics', 'environment' and 'buildings'.
}

3.1.3.3. Sample Size. Initially, 440 participants completed the experiment. 45 respondents who stated that they would not consider a major retrofitting project were screened out. In addition, 37 inattentive participants were screened out after failing the attention test. Of the remaining 358 participants, 122 refused to reveal their political preferences or stated that they did not prefer any particular party. The remaining sample thus consisted of 236 residential homeowners in Switzerland, of whom 183 self-identified with left- or right-wing parties. The other participants belonged to a wide range of parties from the center-left to the center-right of the political spectrum. In order to create a rigorous divide between right- and left-wing so as to increase the comparability of the research with previous literature (Hardisty et al., 2010), the diverse spread of 'centrist'-voters were omitted from the analysis. The descriptive statistics of the sample composition for all experiments can be found in Table 1.

\subsubsection{Results}

A two-way factorial ANCOVA (analysis of covariance) regression was carried out, as detailed in Table 2 . The dependent variable of this between-subject analysis was the importance score of the government benefit as a decision criterion when choosing between different home renovation projects in the $\mathrm{CBC}$ choice experiment. The two fixed factors included in the analysis were (1) the framing of the delivery mechanism of the government benefit and (2) the political orientation of the respondent. All covariates described in the methodological section about the questionnaire design (e.g. demographic variables) were also incorporated into the analysis.

The key finding is that the main effect of the delivery mechanism frame on the importance of the government benefit is not significant in itself $(F(1,168)=1.450, p=0.230)$. Therefore, re-framing a benefit as either a 'tax rebate' or a 'subsidy' has on average no significant influence on the perceived importance of this attribute in homeowners' retrofit choices. However, the interaction term between the delivery mechanism frame and political orientation is revealed as significant $(\mathrm{F}(1,168)=3.893, \mathrm{p}=0.050)$. Therefore, left- and right-wing voters react differently according to whether an equally-sized government benefit is labeled 'tax rebate' or 'subsidy, which supports H1.

Fig. 2 shows the estimated marginal mean scores for each political orientation group under changing delivery mechanism frames. Even though the figure indicates that left-wing voters attach slightly higher importance to government benefits when they are labeled 'subsidy' compared to 'tax rebate', this difference is not significant at the 5\% level. In contrast, right-wing voters pay significantly more attention to government benefits when they are labeled 'tax rebate' instead of 'subsidy'. This difference is significant at the $1 \%$ level.

None of the other demographic and psychometric variables proved to be significantly related to the perceived importance of government benefits. This indicates that differences in environmental concern, numeracy and risk and time preference do not directly influence the weight attached to government benefits in homeowners' retrofit choices $(p>0.05)$.

\subsection{Experiment 2}

The main objective of the second experiment was to analyze whether support for free market liberalism moderates the impact of alternative 'frames in communication' on policy evaluation for a government program targeted at residential energy conservation.

\subsubsection{Methodology and Experimental Procedure}

3.2.1.1. Procedure. All participants of the online experiment were randomly sorted into one of three groups and forwarded an informational text about a new policy program. 
Table 1

Descriptive sample statistics.

\begin{tabular}{|c|c|c|c|c|c|c|c|}
\hline & & \multicolumn{3}{|c|}{ Experiment 1} & \multicolumn{3}{|c|}{ Experiments $2+3$} \\
\hline & & Mean (SD) & Frequency & $\%$ & Mean (SD) & Frequency & $\%$ \\
\hline \multirow[t]{2}{*}{ Polit. affiliation } & Left-wing & & 77 & 42.1 & & & \\
\hline & Right-wing & & 106 & 57.9 & & & \\
\hline \multirow[t]{2}{*}{ Economic liberalism } & Low & & & & & 363 & 60.2 \\
\hline & High & & & & & 240 & 39.8 \\
\hline \multirow[t]{2}{*}{ Gender } & Male & & 127 & 69.4 & & 332 & 55.1 \\
\hline & Female & & 56 & 30.6 & & 271 & 44.9 \\
\hline Age & & $58(11)$ & & & $48(16)$ & & \\
\hline \multirow[t]{7}{*}{ Education } & Undisclosed & & - & - & & 3 & 0.5 \\
\hline & Elementary school & & - & - & & 3 & 0.5 \\
\hline & Secondary school, vocational training or equiv. & & 58 & 31.7 & & 203 & 33.7 \\
\hline & High school or equiv. & & 23 & 12.6 & & 88 & 14.6 \\
\hline & University of applied sciences or equiv. & & 59 & 32.2 & & 158 & 26.2 \\
\hline & University or equiv. & & 30 & 16.4 & & 122 & 20.2 \\
\hline & Doctorate/PhD/MBA & & 13 & 7.1 & & 26 & 4.3 \\
\hline \multirow[t]{6}{*}{ Gross household income } & Undisclosed & & 13 & 7.1 & & 87 & 14.4 \\
\hline & Below 4,880 CHF & & 8 & 4.4 & & 68 & 11.3 \\
\hline & $4,880-7,173$ & & 29 & 15.8 & & 128 & 21.2 \\
\hline & 7,174-9,702 CHF & & 44 & 24.0 & & 117 & 19.4 \\
\hline & $9,703-13,170 \mathrm{CHF}$ & & 57 & 31.1 & & 130 & 21.6 \\
\hline & Over $13170 \mathrm{CHF}$ & & 32 & 17.5 & & 73 & 12.1 \\
\hline \multirow[t]{3}{*}{ Owner-occupancy } & Undisclosed & & 2 & 1.1 & & & \\
\hline & Owner-occupied & & 175 & 95.6 & & & \\
\hline & Non-owner-occupied & & 6 & 3.3 & & & \\
\hline \multirow[t]{3}{*}{ Landlord/tenant } & Undisclosed & & & & & 2 & 0.3 \\
\hline & Landlord & & & & & 246 & 40.8 \\
\hline & Tenant & & & & & 355 & 58.9 \\
\hline Building age & & $29(20)$ & & & & & \\
\hline \multirow[t]{7}{*}{ Heating system } & Oil & & 68 & 37.2 & & & \\
\hline & Wood & & 10 & 5.5 & & & \\
\hline & Heat pump & & 46 & 25.1 & & & \\
\hline & Electricity & & 10 & 5.5 & & & \\
\hline & Gas & & 37 & 20.2 & & & \\
\hline & Teleheating & & 1 & 0.5 & & & \\
\hline & Others & & 11 & 6.0 & & & \\
\hline
\end{tabular}

3.2.1.2. Experimental Groups. The experiment consisted of two experimental groups and one control group. The control group received basic information about a subsidy program which explained that

Table 2

Results of two-way ANCOVA - between-subject effects for the impact of frames and political orientation on the perceived importance of a benefit.

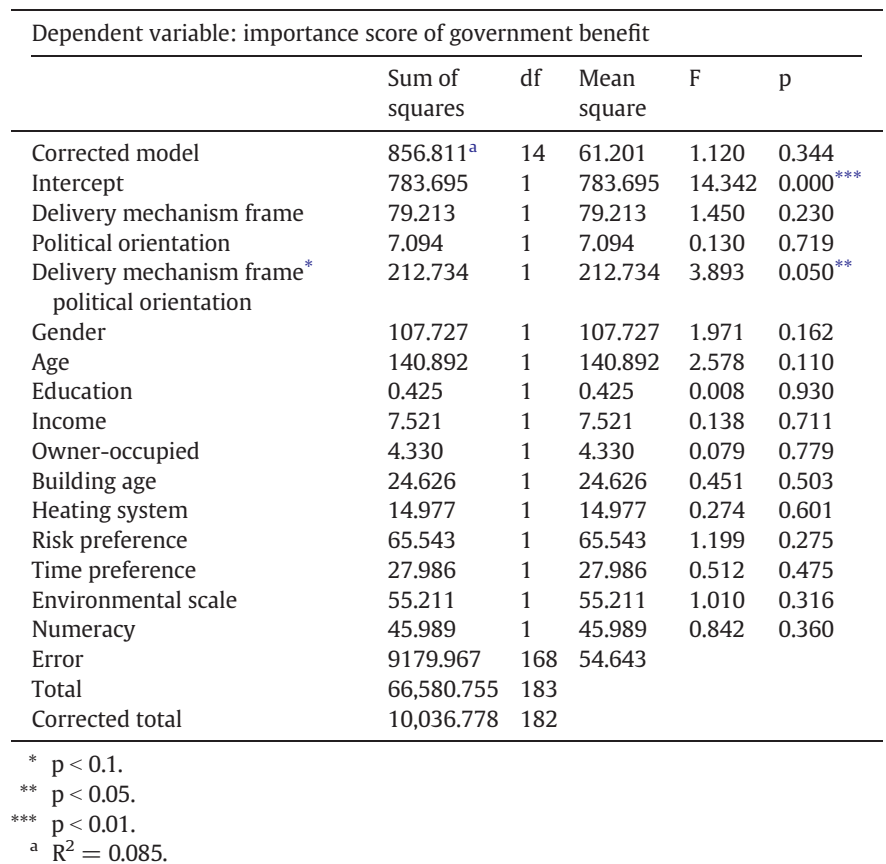

reducing residential energy consumption is an element of the Swiss Energy Strategy 2050 (a Swiss government program). Further, participants were informed that in order to incentivize energy-saving home improvement measures, the offer of a cash subsidy was currently under debate. The amount of the average government payment per

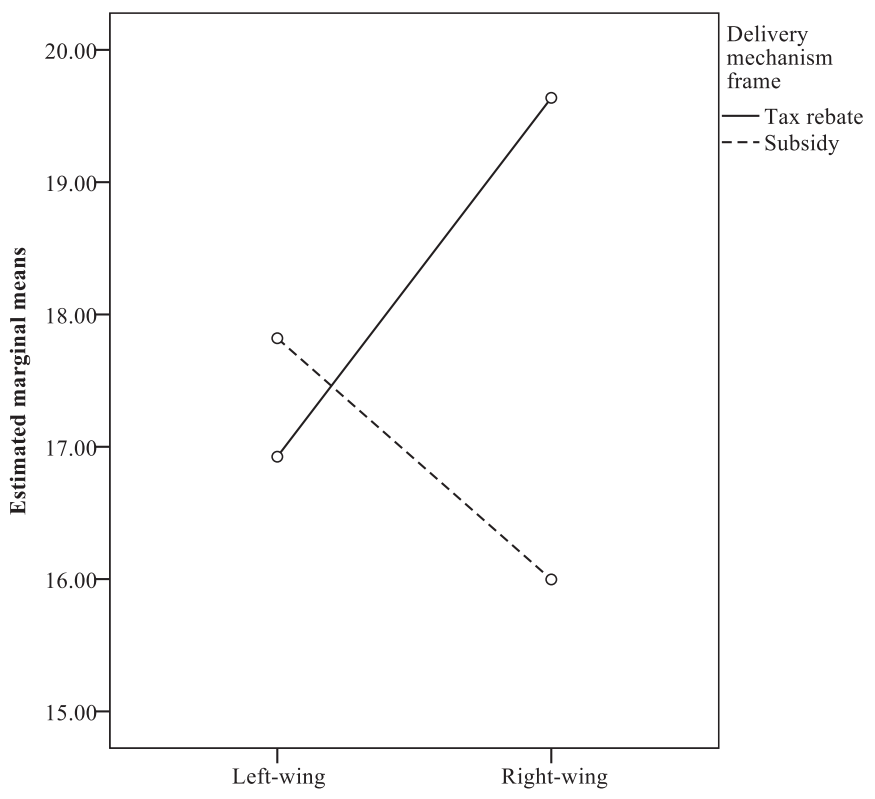

Fig. 2. Mean importance scores of government benefits by party identification and experimental condition. 
eligible renovation project was described as 10,000 CHF. The text presented to the control group was written in an entirely neutral language without normative judgment. The same 'basic' information given to the control group was also presented to each framing experimental group; however, the manipulated texts were extended with further information: the text in the 'economic' frame experimental group focused on describing the economic benefits of energy saving home improvements. Specifically, it was highlighted that home retrofits can benefit both landlords and tenants by reducing space heating costs (on average by $1,500 \mathrm{CHF}$ per year for a single family home). Further, respondents were informed that by reducing dependence on fossil fuel imports, landlords and tenants could protect themselves from rising fuel prices. In addition, it was emphasized that building renovation programs benefit local craftsmen and thus create local workplaces. The text in the 'environmental' frame experimental group, in contrast, only presented arguments related to the ecological advantages of energy saving. In this group, respondents were informed that home retrofits lead to significant reductions in $\mathrm{CO}_{2}$ emissions (on average, three tons per year for a single family home with oil heating). The text also suggested that by reducing fossil fuel consumption, landlords and tenants contribute to combating global climate change. Further, it was pointed out that energy-saving measures create local environmental benefits. The exact wording of the communication frames can be found in the Appendix B.

\subsubsection{Measures}

3.2.2.1. Policy Evaluation. Respondents' level of agreement with the introduction of the new policy program functioned as the dependent variable. In each experimental group, respondents were asked: "Would you support the subsidy program described above?" After the information was provided, respondents could indicate their consent with this government program on a 6 -point Likert scale ranging from " $1=$ Completely against this program" to " $6=$ Completely in favor of this program".

3.2.2.2. Communication Frame. A categorical variable indicated which experimental group the respondents belonged to (economic frame, environmental frame or neutral text/control group).

3.2.2.3. Free Market Liberalism. Respondents were classified according to their endorsement of free market liberalism. Based on a standard question from the political science literature, we asked respondents to report their attitudes toward government spending on a 7-point Likert scale ranging from "The government should provide far fewer services and reduce spending a lot" to "The government should provide many more services and increase spending a lot" (Jacoby, 2000). Whereas Jacoby (2000) used a single-item scale for government spending, we also measured respondents' preferences for government intervention in the market economy. The main reason for this additional item was that home retrofit subsidies not only increase government spending, but also require interventions in the real estate market. The self-reported measure for free market liberalism was derived from a questionnaire by Heath and Gifford (2006). We asked participants whether they agreed with the following statement: "A free market economy with as little government intervention as possible works best to meet human needs" (7-point Likert scale, from $1=$ Don't agree at all to $7=$ Completely agree). In order to avoid potential priming effects, questions about abstract political attitudes were presented on the same page as the demographic questions. We integrated both self-reported measures (after having reverse-scaled the first item) to build a free market liberalism scale. Simple bivariate correlation analysis revealed that the Pearson correlation coefficient between right-/left-wing political orientation and respondents' scores on the free market liberalism scale was 0.6 and significant $(p<0.01)$. Given that right-/left-wing party affiliation and self-reported scores for market liberalism are strongly correlated, we conclude that they are both suitable measures for use in analyzing the underlying construct 'political orientation'.
Table 3

Results of two-way ANCOVA - between-subject effects for the impact of frames and free market liberalism on policy support.

\begin{tabular}{|c|c|c|c|c|c|}
\hline \multicolumn{6}{|c|}{ Dependent variable: policy support } \\
\hline & $\begin{array}{l}\text { Sum of } \\
\text { squares }\end{array}$ & df & $\begin{array}{l}\text { Mean } \\
\text { square }\end{array}$ & $\mathrm{F}$ & $\mathrm{p}$ \\
\hline Corrected model & $121.274^{\mathrm{a}}$ & 10 & 12.127 & 9.056 & 0.000 \\
\hline Intercept & 287.847 & 1 & 287.847 & 214.944 & $0.000^{* * * *}$ \\
\hline Communication frame & 9.372 & 2 & 4.686 & 3.499 & $0.031^{* *}$ \\
\hline Free market liberalism & 97.039 & 1 & 97.039 & 72.462 & $0.000^{* * *}$ \\
\hline $\begin{array}{l}\text { Frame* free market } \\
\text { liberalism }\end{array}$ & 3.205 & 2 & 1.602 & 1.197 & 0.303 \\
\hline Gender & 0.009 & 1 & 0.009 & 0.007 & 0.933 \\
\hline Age & 2.475 & 1 & 2.475 & 1.848 & 0.175 \\
\hline Education & 3.489 & 1 & 3.489 & 2.605 & 0.107 \\
\hline Income & 0.052 & 1 & 0.052 & 0.038 & 0.845 \\
\hline Landlord/tenant & 0.890 & 1 & 0.890 & 0.665 & 0.415 \\
\hline Error & 792.789 & 592 & 1.339 & & \\
\hline Total & $12,560.000$ & 603 & & & \\
\hline Corrected total & 914.063 & 602 & & & \\
\hline $\begin{array}{l}\mathrm{R}^{2}=0.133 \\
\mathrm{p}<0.1 \\
\mathrm{p}<0.05 \\
\mathrm{p}<0.01\end{array}$ & & & & & \\
\hline
\end{tabular}

3.2.2.4. Landlord/Tenant. Given that homeowners may favor the proposed policy out of self-interest, a dichotomous variable was included to identify whether the respondent in question was a landlord or a tenant.

3.2.2.5. Other Covariates. The demographic variables gender, age, education and gross household income were included as covariates.

\subsubsection{Sampling and Data Quality}

As in the first experiment, data collection was handled by Intervista, a leading Swiss market research agency. Initially, 900 individuals took part in the experiment. In contrast to the first experiment, not only homeowners but also apartment owners and tenants were included in the sample in order to permit the investigation of policy evaluation among the general population. In order to increase data quality, we again implemented a simple attention check, as in the first experiment. Based on this test, we screened out 18 inattentive respondents, leaving 882 participants. The participants were split into three equal-sized groups according to their score for free market liberalism (low, medium,

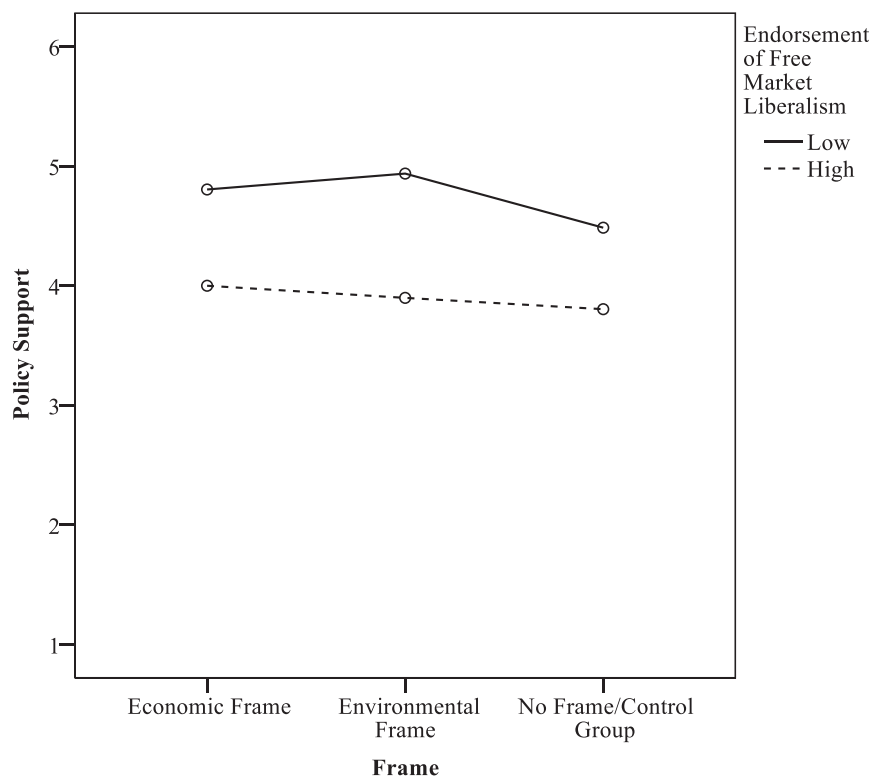

Fig. 3. Policy support by level of free market liberalism and experimental condition. 
high). As with experiment 1 , we only included the two 'extreme' groups in the analysis which scored high or low on the free market liberalism scale. The objective of this approach was to obtain a clear-cut division between supporters of economic interventionism vs. supporters of free market liberalism. The final sample size was 603 participants.

\subsubsection{Results}

A two-way factorial ANCOVA regression analysis was carried out in which respondents' level of agreement regarding the introduction of the new policy program functioned as the dependent variable. The two fixed factors of the ANCOVA analysis were the 1) communication frames including the neutral control group, and 2) individual scores on the free market liberalism scale. Estimation results are reported in Table 3 . The data shows that communication frames significantly influence individuals' agreement with the policy $(F(2,592)=3.499, \mathrm{p}=$ 0.031 ). Further, the results show that respondents' degree of free market liberalism has a significant impact on how favorably the policy is evaluated $(\mathrm{F}(1,592)=72.462, \mathrm{p}=0.000)$. However, this statistically significant difference between the supporters of economic interventionism (i.e. those who score low on the liberalism scale) and advocates of free market liberalism is independent of the frame in question $(F(2$, 592) $=1.197, \mathrm{p}=0.303$ ).

As a robustness check, we carried out a univariate ANOVA analysis for each ideological group (low/high score on free market liberalism scale) in isolation (table not included here for reasons of brevity). We find that the impact of the communication frames on policy evaluation, which is statistically significant on average (see Table 3), is in fact only significant for individuals who score low in terms of market liberalism, i.e. have more favorable attitudes toward government spending and regulation $(\mathrm{F}(2,355)=5.565, \mathrm{p}=0.004)$. While there is no statistically significant difference between the two communication frames (economic or environmental), both frames significantly increase policy support among supporters of economic interventionism in comparison to the neutral control text. In contrast, Fig. 3 shows that neither the economic or environmental frame have any statistically significant impact on policy support among proponents of free market liberalism, i.e. those that have less favorable attitudes toward government spending/ economic interventionism $(\mathrm{F}(2,232)=0.662, \mathrm{p}=0.538)$. Fig. 3 also shows graphically that supporters of economic interventionism agree on average more strongly with the introduction of the government benefit than endorsers of market liberalism (independent of the communication frame in question). Therefore, it can be stated that the 'frames in communication' related to the subsidy program only have a significant impact on policy evaluation when the frames are consistent with the respondents' prior political views about economic individualism and government spending. Thus, $\mathrm{H} 2$ can be confirmed with some reservations: free market liberalism is shown to influence policy evaluation, but it does not moderate the magnitude of the framing effect. Among those that hold pre-existing favorable attitudes towards government spending and regulation, communication frames have a significant positive influence on policy evaluation in comparison to a neutral text. However, in this case the impact of the communication frame on policy evaluation is indifferent of whether the communication frame highlights economic or environmental benefits.

\subsection{Experiment 3}

The third experiment investigates if the presentation of mixed arguments related to government spending changes the influence of the initial framing effect. Although the results of experiment 2 reveal that the frames have no significant effect on individuals who score high on the free market liberalism scale (i.e. those that favor less governmental spending and regulation), motivated reasoning could potentially lead to even lower levels of agreement regarding the introduction of a new subsidy program for incentivizing energy-saving home improvement measures after cognitive deliberation. In the case of citizens who favor
Table 4

Repeated measures ANCOVA - within subject effects.

\begin{tabular}{lllll}
\hline & $\mathrm{df}$ & $\mathrm{F}$ & $\mathrm{p}$ & $\eta^{2}$ \\
\hline Time & 1 & 0.833 & 0.362 & 0.001 \\
Time* gender & 1 & 2.122 & 0.146 & 0.004 \\
Time* age & 1 & 0.004 & 0.953 & $0.000^{* * *}$ \\
Time* education & 1 & 5.879 & $0.016^{* *}$ & 0.010 \\
Time* income & 1 & 0.145 & 0.704 & 0.000 \\
Time* landlord/tenant & 1 & 0.707 & 0.401 & 0.001 \\
Time* communication frame & 2 & 1.098 & 0.334 & 0.004 \\
Time* free market liberalism & 1 & 1.033 & 0.310 & 0.002 \\
Time* frame* free market liberalism & 2 & 0.337 & 0.714 & 0.001 \\
Error & 592 & & & \\
\hline
\end{tabular}

${ }^{*} \mathrm{p}<0.1$.

** $\mathrm{p}<0.05$.

*** $\mathrm{p}<0.01$.

an increase in governmental spending and regulation, the question is if in-depth reasoning reinforces the positive effects of the communication frames as identified in experiment 2.

\subsubsection{Methodology and Experimental Procedure}

3.3.1.1. Procedure. We conducted a within-subject analysis with the same group of participants as in experiment 2 . After reading the initial frame (experiment 2) and stating their opinion about the planned policy program, all participants were re-directed to a new page on which they were encouraged to justify their attitudes toward government spending. First, participants were asked to write down at least three thoughts about direct subsidies in a free mental association task. Second, they were presented with three arguments in favor of and three arguments against increased government spending. The order of the pros and cons were randomized (the wording is presented in the Appendix C). In total, the cognitive deliberation tasks took around $10 \mathrm{~min}$ to complete. The length of these tasks was therefore similar to the group discussions organized by Druckman and Nelson (2003), which were up to 6 min long and led to a significant reversal of framing effects. After data collection, an ex-post $t$-test was conducted to ensure that there were no significant differences between respondents' average level of support for either pros and cons. The results of the $t$-test revealed that the mean levels of agreement for the pros and cons $\left(\mathrm{M}_{\text {pro }}=3.247, \mathrm{SD}=0.800, \mathrm{M}_{\text {contra }}=3.1859, \mathrm{SD}=0.801\right)$ were not

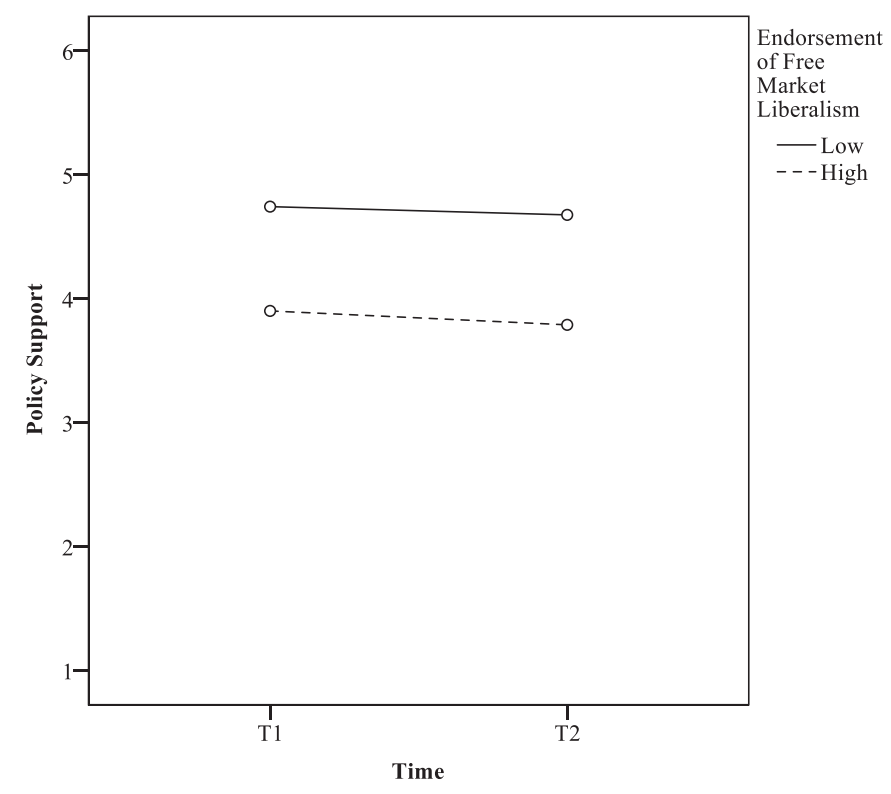

Fig. 4. Policy support at $\mathrm{T} 1$ and $\mathrm{T} 2$ by level of free market liberalism. 


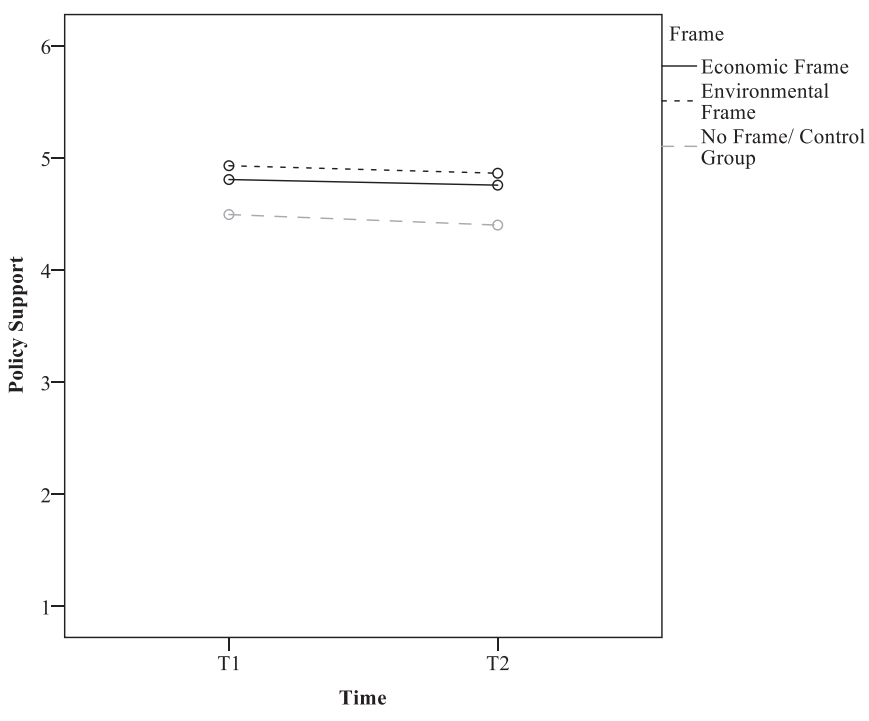

Fig. 5. Policy support at $\mathrm{T} 1$ and $\mathrm{T} 2$ by experimental condition in the economic interventionism group.

significantly different $(t=-1.606, \mathrm{p}>0.1)$. This finding indicates that the presented arguments were not biased.

3.3.1.2. Measures. After the cognitive deliberation tasks, respondents were again shown the same question as in experiment 2 . Thus, they were asked to state their opinion about the planned government policy program using a 6-point Likert scale ranging from " $1=$ Completely against this program" to " $6=$ Completely in favor of this program". The dependent variable for this experiment was the level of agreement with this statement before and after cognitive deliberation.

\subsubsection{Results}

In contrast to experiments 1 and 2, we conducted repeated measures ANCOVA with time as the within-subject factor and measured respondents' level of agreement with the policy before and after the cognitive deliberation task. The results of the analysis (see Table 4) show that the time spent on cognitive deliberation has no significant influence on respondents' evaluation of the policy $(\mathrm{F}(1,592)=$ 0.833, $\mathrm{p}=0.362$, partial $\left.\eta^{2}=0.001\right)$. Furthermore, there is no

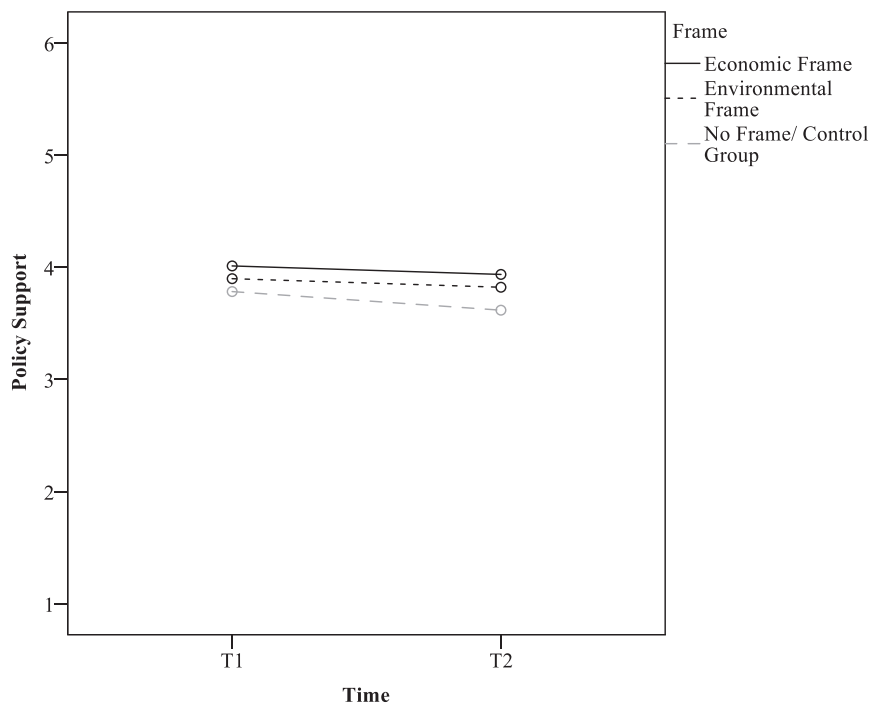

Fig. 6. Policy support at $\mathrm{T} 1$ and $\mathrm{T} 2$ by experimental condition in the free market liberalism group. significant interaction effect between time and the framing effect. None of the other interaction effects are significant either, except for education $\left(\mathrm{F}(1,592)=5.879, \mathrm{p}=0.016\right.$, partial $\left.\eta^{2}=0.010\right)$. While the partial $\eta^{2}$ as a measure of effect size is small according to the Cohen conventions (Cohen, 2013), a more detailed analysis of the relationship between education and likelihood of opinion change could be an avenue for future research.

Fig. 4 exhibits the same results as Table 4 in a graphical format. T1 and $\mathrm{T} 2$ denote the levels of agreement at the time before and after cognitive deliberation. Again, the results indicate that no statistically significant opinion change occurs, and thus preferences remain stable over time both in the economic interventionism and free market liberalism groups. Figs. 5 and 6 show the isolated results for each group (endorsement of economic interventionism vs. free market liberalism), split according to the frames. Among respondents that favor more governmental spending and regulation, agreement with the government spending program continues to be highest among the participants which were exposed to framed texts. Support for the policy program is lowest in the control group, both before and after cognitive deliberation. Among supporters of free market liberalism (i.e. those that favor economic individualism and less government spending), the communication frames have no significant influence on the individual level of agreement at any point in time. Taken together, these results show that preferences remain stable over time, thus $\mathrm{H} 3$ is rejected.

\section{Discussion and Conclusions}

The overall objective of the experiments described herein is to analyze how political orientation moderates the influence of framing effects on policy evaluation. Two experiments investigate framing effects in both policy delivery mechanism and policy communication in the context of a residential energy conservation program. In addition, a third experiment explores the temporal dynamics of framing effects over time.

The first experiment investigates how party identification moderates differences in perception of a government benefit for energy saving home improvements of equivalent magnitude, described as either a 'tax rebate' or a 'subsidy'. The results show that labeling the delivery mechanism as a 'tax rebate' leads to significantly higher perceived importance of the benefit among right-wing voters, while the framing effect is not significant for left-wing voters. This finding has some practical implications for policy design: considering that changes in the description of a policy delivery mechanism do not influence all citizens equally, they can be expected to have differential effects on policy uptake across different segments of the population. In this context, policy makers could potentially learn from customer segmentation strategies in marketing to 'tailor' policy design to their expected audiences.

The second experiment analyzes how pre-existing beliefs about economic individualism and government spending moderate the influence of a frame in communication (which focuses on economic or environmental benefits) on public policy support. The results show that, in comparison with the control group (neutral text), both communication frames significantly increase the preference for a policy among individuals who have pre-existing positive attitudes toward government spending. However, the influence of the communication frame on policy support in this group is indifferent to whether the frame focuses on economic or environmental aspects. Among supporters of free market liberalism, the communication frames have no impact on policy evaluations, even if the frame highlights economic benefits.

These results have several implications for policy communication. First, the results show that communication frames affect public support for environmental policy instruments, but only among citizens who are in general supportive of government intervention in the economy. Justifying environmental policy in public discourse by referring to economic benefits is often suggested as a measure for increasing public policy support. However, the results of the current study imply that 're-framing' strategies are unlikely to change the opinions of individuals who 
are opposed to government spending and economic interventionism in general.

Second, the findings from both experiments 1 and 2 show that an individual's political orientation moderates the influence of framing effects on environmental policy evaluation. These results imply that citizens' reactions to communication frames are consistent with their pre-existing political orientation, and thus the impact of frames on public opinion formation is limited to a certain extent. These findings mitigate concerns raised by other authors that policy-related framing effects question the decision-making competence of citizens (for a review, see Druckman, 2001). Furthermore, the results of experiment 2 add another piece of evidence to the literature that suggests that there is potential ideological conflict between free market liberalism and environmental policy instruments.

Another research objective was to investigate the temporal dynamics of framing effects. The third experiment shows that the likelihood of choice switching is low, which indicates that framing effects - if they occur - remain persistent over time. This finding has implications for research and practice in terms of public opinion formation: considering individuals' reluctance to change their opinions over time, the initial frame presented to citizens is likely to have disproportionate influence on their opinion formation. This indicates that politicians or interest groups that seek to shape public discourse about environmental policy should strive to publicize their frames in communication at an early point in time.

As with any study, this research is subject to some limitations. Owing to the experimental nature of the research, the usual methodological limitations of stated preference studies apply. We tried, however, to mitigate any hypothetical bias by carefully designing the experimental setup and surveying real decision makers, rather than relying on a student sample. A possible area for further research would be to investigate the support for energy conservation policy in the subgroup of landlords, which might rate the potential financial benefits higher than political orientation. Another limitation of this research is that the time between the presentation of the initial frame, the presentation of the mixed arguments, and the second preference elicitation was relatively short (approximately $10 \mathrm{~min}$ ). Although the time span for the reasoning tasks was similar to the length of group discussions in previous studies investigating the persistence of choice-framing effects (e.g. Druckman and Nelson, 2003), the chosen research design does not permit the measurement of long-term preferences change. Therefore, a potential avenue for future research would be to analyze whether framing effects remain persistent over longer time spans (e.g. months, years).

\section{Acknowledgments}

We would like to thank the Swiss Federal Office of Energy (BFE) for funding the survey described in this research paper under Contract No. SI/501343-01. This research effort is part of the activities of the SCCER CREST (Swiss Competence Center for Energy Research), which is financially supported by the Swiss Commission for Technology and Innovation (CTI) under Grant No. 466 KTI.2014.0114.

We thank two anonymous reviewers for their constructive feedback on an earlier version of this paper.

\section{Appendix A. Item Wording (Translated to English From German)}

\begin{tabular}{lll}
\hline Variable & Scale & Wording English \\
\hline Time & Binary (1 & $1=3,400$ CHF at the end of this month \\
preference & or 2) & $2=3,800$ CHF at the end of next month \\
& & $1=100$ CHF now \\
& & $1=140$ CHF next year \\
& & $2=100$ CHF now \\
& Binary (1 1 & "Suppose you participated in a lottery. Which of the \\
Risk & following two options would you choose?" \\
preference 2$)$ &
\end{tabular}

(continued)

\begin{tabular}{|c|c|c|c|}
\hline Variable & Scale & \multicolumn{2}{|l|}{ Wording English } \\
\hline & & \multicolumn{2}{|c|}{$\begin{array}{l}1=80 \% \text { chance to win } 45 \mathrm{CHF} \text { (else } 0 \mathrm{CHF} \text { ), } 2=95 \% \\
\text { chance to win } 30 \mathrm{CHF} \text { (else } 0 \mathrm{CHF} \text { ) } \\
\text { "You can toss a coin for free. You will get either "heads" } \\
\text { or "tails". You may choose one of the following two } \\
\text { options." } \\
1=\text { For heads you receive } 2,000 \text { CHF and for tails you } \\
\text { receive } 200 \mathrm{CHF} \\
2=\text { You win 1,000 CHF with either heads or tails } \\
\text { "Suppose you participated in a lottery. Which of the } \\
\text { following two options would you choose?" } \\
1=\text { You get a lottery ticket with a } 20 \% \text { chance of } \\
\text { winning } 130 \text { CHF (if you lose, you get } 0 \text { CHF) } \\
2=\text { You get a lottery ticket with a } 25 \% \text { chance of } \\
\text { winning } 100 \text { CHF (if you lose, you get } 0 \text { CHF) }\end{array}$} \\
\hline \multicolumn{3}{|c|}{ Numeracy questionnaire } & $\begin{array}{l}\text { Correct } \\
\text { response }\end{array}$ \\
\hline \multicolumn{3}{|c|}{$\begin{array}{l}\text { Suppose you had } 200 \text { CHF in a savings account and the interest rate } \\
\text { was } 10 \% \text { per year. After } 2 \text { years, how much would you have on } \\
\text { this account in total (in CHF)? }\end{array}$} & 242 \\
\hline \multicolumn{3}{|c|}{$\begin{array}{l}\text { Suppose you had } 100 \text { CHF in a savings account and the interest rate } \\
\text { was } 2 \% \text { per year. After } 10 \text { years, how much do you think you } \\
\text { would have in the account if you left the money to grow? ( } 1 \text { ) } \\
>110 \text { CHF; (2) exactly } 110 \text { CHF; }(3)<110 \text { CHF; (4) do not know }\end{array}$} & 1 \\
\hline \multicolumn{3}{|c|}{$\begin{array}{l}\text { Imagine that the interest rate on your savings account was } 1 \% \text { per } \\
\text { year and inflation was } 2 \% \text { per year. After } 1 \text { year, how much would } \\
\text { you be able to buy with the money in this account? (1) More than } \\
\text { today; (2) exactly the same; (3) less than today; (4) do not know }\end{array}$} & 3 \\
\hline
\end{tabular}

\section{Appendix B. Wording of Communication Frames}

\section{B.1. Neutral Information}

"One element of the Swiss Energy Strategy is the reduction of residential energy consumption. Therefore, a cash subsidy for energy-saving home improvements is currently under discussion. The average cost of the subsidy would amount to 10,000 CHF per eligible renovation project."

\section{B.2. Economic Frame}

"One element of the Swiss Energy Strategy is the reduction of residential energy consumption. Energy-saving home improvements offer several benefits: 1) They reduce the space heating expenses of both homeowners and renters. The average cost-saving for a single family home is approx. 1,500 CHF per year. 2) Dependence on fossil fuel imports is reduced: both homeowners and renters become more independent from increases in fuel prices. 3) Home improvements create local workplaces: renovation projects benefit local craftsmen. Therefore, a cash subsidy for energy-saving home improvements is currently under discussion. The average cost of the subsidy would amount to 10,000 CHF per eligible renovation project."

\section{B.3. Environmental Frame}

"One element of the Swiss Energy Strategy is the reduction of residential energy consumption. Energy-saving home improvements offer several benefits: 1 ) They reduce the $\mathrm{CO}_{2}$ emissions of both homeowners and renters. The average emission saving for a single family home is approx. 3 tons of $\mathrm{CO}_{2}$ per year. 2) Dependence on fossil fuel imports is reduced, which contributes to combating global climate change. 3) Home improvements benefit the local environment: the local natural environment is less exposed to harmful emissions. Therefore, a cash subsidy for energy-saving home improvements is currently under discussion. The average cost of the subsidy would amount to $10,000 \mathrm{CHF}$ per eligible renovation project." 


\section{Appendix C. Wording of Arguments in Favor of and Against Govern- ment Spending}

\section{Text}

Pro Government subsidies disproportionally benefit the weaker members of our society.

Subsidies can help to solve important social and environmental issues. Government interventions can help to solve problems when free markets fail.

Contra Government interventions negatively affect the efficiency of a free market economy.

Increases in government subsidy programs will result in the uncontrollable growth of federal budget expenses. Direct subsidies are often ineffective at solving societal problems.

\section{Note: The order of the items was randomized.}

\section{References}

Beattie, J., Loomes, G., 1997. The impact of incentives upon risky choice experiments. J. Risk Uncertain. 14 (2), 155-168.

Bell, D., 2002. How can political liberals be environmentalists? Pol. Stud. 50 (4), 703-724.

Bernauer, T., McGrath, L.F., 2016. Simple reframing unlikely to boost public support for climate policy. Nat. Clim. Chang. 6, 680-683.

BFE, 2013a. Botschaft zum ersten Massnahmenpaket der Energiestrategie. p. 2050.

BFE, 2013b. Energieforschung 2012 - Überblicksberichte. Retrieved from. http://www. bfe.admin.ch.

Bochsler, D., Hänggli, R., Häusermann, S., 2015. Introduction: consensus lost? Disenchanted democracy in Switzerland. Swiss Am. Polit. Sci. Rev. 21 (4), 475-490.

Bornstein, N., Lanz, B., 2008. Voting on the environment: price or ideology? Evidence from Swiss referendums. Ecol. Econ. 67 (3), 430-440.

Burks, S., Carpenter, J., Götte, L., Rustichini, A., 2012. Which measures of time preference best predict outcomes: evidence from a large-scale field experiment. J. Econ. Behav. Organ. 84 (1), 308-320.

Camerer, C.F., Hogarth, R.M., 1999. The effects of financial incentives in experiments: a review and capital-labor-production framework. J. Risk Uncertain. 19 (1-3), 7-42.

Chong, D., Druckman, J.N., 2007a. Framing theory. Annu. Rev. Polit. Sci. 10, 103-126.

Chong, D., Druckman, J.N., 2007b. A theory of framing and opinion formation in competitive elite environments. Aust. J. Commun. 57 (1), 99-118.

Chong, D., Druckman, J.N., 2010. Dynamic public opinion: communication effects over time. Am. Polit. Sci. Rev. 104 (04), 663-680.

Chong, D., Druckman, J.N., 2012. Counterframing effects. J. Polit. 75 (1), 1-16

Chrzan, K., Orme, B., 2000. An Overview and Comparison of Design Strategies for Choicebased Conjoint Analysis. Sawtooth Software Research Paper Series.

Cohen, J., 2013. Statistical Power Analysis for the Behavioral Sciences. (2, revised ed. Routledge.

Cook, J., Lewandowsky, S., 2016. Rational irrationality: modeling climate change belief polarization using Bayesian networks. Top. Cogn. Sci. 8 (1), 160-179.

De Vreese, C., 2004. The effects of strategic news on political cynicism, issue evaluations, and policy support: a two-wave experiment. Mass Commun. Soc. 7 (2), 191-214.

De-Shalit, A., 1995. Is liberalism environment-friendly? Soc. Theory Pract. 21 (2) 287-314.

Donkers, B., Melenberg, B., Van Soest, A., 2001. Estimating risk attitudes using lotteries: a large sample approach. J. Risk Uncertain. 22 (2), 165-195.

Druckman, J.N., 2001. The implications of framing effects for citizen competence. Polit. Behav. 23 (3), 225-256.

Druckman, J.N., Nelson, K.R., 2003. Framing and deliberation: how citizens' conversations limit elite influence. Am. J. Polit. Sci. 47 (4), 729-745.

Druckman, J.N., Fein, J., Leeper, T.J., 2012. A source of bias in public opinion stability. Am. Polit. Sci. Rev. 106 (02), 430-454

Duckitt, J., 2001. A dual-process cognitive-motivational theory of ideology and prejudice Adv. Exp. Soc. Psychol. 33, 41-113.

Entman, R.M., 1993. Framing: toward clarification of a fractured paradigm. Aust. J. Commun. 43 (4), 51-58.

Epley, N., Gneezy, A., 2007. The framing of financial windfalls and implications for public policy. J. Socio-Econ. 36 (1), 36-47.

Epley, N., Mak, D., Idson, L.C., 2006. Bonus or rebate?: the impact of income framing on spending and saving. J. Behav. Decis. Mak. 19 (3), 213-227.

Faricy, C., Ellis, C., 2014. Public attitudes toward social spending in the United States: the differences between direct spending and tax expenditures. Polit. Behav. 36 (1), 53-76.

Feldman, S., Johnston, C., 2014. Understanding the determinants of political ideology: implications of structural complexity. Pol. Psychol. 35 (3), 337-358.

Fisher, R.J., 1993. Social desirability bias and the validity of indirect questioning. J. Consum. Res. 303-315.

Frederick, S., 2005. Cognitive reflection and decision making. J. Econ. Perspect. 19 (4), 25-42.

Gerber, A., Gimpel, J.G., Green, D.P., Shaw, D.R., 2007. The Influence of Television and Radio Advertising on Candidate Evaluations: Results From a Large Scale Randomized Experiment. Unpublished paper. Yale University.

Green, P.E., Srinivasan, V., 1990. Conjoint analysis in marketing: new developments with implications for research and practice. J. Mark. 3-19.
Hardisty, D.J., Johnson, E.J., Weber, E.U., 2010. A dirty word or a dirty world? Attribute framing, political affiliation, and query theory. Psychol. Sci. 21 (1), 86-92.

Hart, P.S., Nisbet, E.C., 2012. Boomerang effects in science communication: how motivated reasoning and identity cues amplify opinion polarization about climate mitigation policies. Commun. Res. 39 (6), 701-723.

Heath, Y., Gifford, R., 2006. Free-market ideology and environmental degradation the case of belief in global climate change. Environ. Behav. 38 (1), 48-71.

Heinzle, S.L., Wüstenhagen, R., 2012. Dynamic adjustment of eco-labeling schemes and consumer choice-the revision of the EU energy label as a missed opportunity? Bus. Strateg. Environ. 21 (1), 60-70.

Heywood, A., 2012. Political Ideologies: An Introduction. Palgrave Macmillan.

International Energy Agency, 2013. Transition to Sustainable Buildings: Strategies and Opportunities to 2050. Retrieved from. www.iea.org.

Iyengar, S., 1994. Is anyone responsible? How Television Frames Political Issues. University of Chicago Press.

Jacoby, W.G., 2000. Issue framing and public opinion on government spending. Am. J. Polit. Sci. 750-767.

Jost, J.T., Glaser, J., Kruglanski, A.W., Sulloway, F.J., 2003. Political Conservatism as Motivated Social Cognition. American Psychological Association.

Jost, J.T., Federico, C.M., Napier, J.L., 2009. Political ideology: its structure, functions, and elective affinities. Annu. Rev. Psychol. 60, 307-337.

Kahan, D. 2010. Fixing the communications failure. Nature 463 (7279), 296-297.

Kahan, D.M., 2013. Ideology, motivated reasoning, and cognitive reflection. Judgm. Decis. Mak. 8 (4), 407-424.

Kahneman, D., Tversky, A., 1979. Prospect theory: An analysis of decision under risk. Econometrica 263-291.

Klar, S., Robison, J., Druckman, J.N., 2013. Political dynamics of framing. New Directions in Media and Politics. Routledge, pp. 173-192.

Klauer, B., Manstetten, R., Petersen, T., Schiller, J., 2013. The art of long-term thinking: a bridge between sustainability science and politics. Ecol. Econ. 93, 79-84.

Kunda, Z., 1990. The case for motivated reasoning. Psychol. Bull. 108 (3), 480.

LeBoeuf, R.A., Shafir, E., 2003. Deep thoughts and shallow frames: on the susceptibility to framing effects. J. Behav. Decis. Mak. 16 (2), 77-92.

Levin, I.P., Schneider, S.L., Gaeth, G.J., 1998. All frames are not created equal: a typology and critical analysis of framing effects. Organ. Behav. Hum. Decis. Process. 76 (2), $149-188$

Levin, I.P., Gaeth, G.J., Schreiber, J., Lauriola, M., 2002. A new look at framing effects: distribution of effect sizes, individual differences, and independence of types of effects. Organ. Behav. Hum. Decis. Process. 88 (1), 411-429.

Lockwood, M., 2011. Does the framing of climate policies make a difference to public support? Evidence from UK marginal constituencies. Clim. Pol. 11 (4), 1097-1112.

Lozza, E., Carrera, S., Bosio, A.C., 2010. Perceptions and outcomes of a fiscal bonus: framing effects on evaluations and usage intentions. J. Econ. Psychol. 31 (3), 400-404.

Lusardi, A., Mitchell, O.S., 2011. Financial literacy around the world: an overview. J. Pension Econ. Fin. 10 (04), 497-508.

Madrian, B.C., 2014. Applying insights from behavioral economics to policy design. Annu. Rev. Econ. 6 (1), 663-688.

Neumann, L.J., Morgenstern, O., 1947. Theory of Games and Economic Behavior. vol. 60. Princeton University Press, Princeton.

Petrovic, N., Madrigano, J., Zaval, L., 2014. Motivating mitigation: when health matters more than climate change. Clim. Chang. 126 (1-2), 245-254.

Rossi, P.E., Allenby, G.M., 2003. Bayesian statistics and marketing. Mark. Sci. 22 (3), 304-328.

Sbci, U., 2009. Buildings and Climate Change: A Summary for Decision-makers. United Nations Environmental Programme, Sustainable Buildings and Climate Initiative, Paris, pp. 1-62.

Scrase, J.I., Ockwell, D.G, 2010. The role of discourse and linguistic framing effects in sustaining high carbon energy policy-an accessible introduction. Energ Policy 38 (5), 2225-2233.

Slothuus, R., De Vreese, C.H., 2010. Political parties, motivated reasoning, and issue framing effects. J. Polit. 72 (3), 630-645.

Smith, S.M., Levin, I.P., 1996. Need for cognition and choice framing effects. J. Behav. Decis. Mak. 9 (4), 283-290.

Söderbaum, P., 1999. Values, ideology and politics in ecological economics. Ecol. Econ. 28 (2), 161-170.

Taber, C.S., Lodge, M., 2006. Motivated skepticism in the evaluation of political beliefs. Am. J. Polit. Sci. 50 (3), 755-769.

Taber, C.S., Lodge, M., Glathar, J., 2001. The motivated construction of political judgments. Citizens and Politics: Perspectives From Political Psychology. Cambridge University Press, pp. 198-226.

Taber, C.S., Cann, D., Kucsova, S., 2009. The motivated processing of political arguments. Polit. Behav, 31 (2), 137-155.

Tewksbury, D., Jones, J., Peske, M.W., Raymond, A., Vig, W., 2000. The interaction of news and advocate frames: manipulating audience perceptions of a local public policy issue. J. Mass Commun. O. 77 (4), 804-829.

Tversky, A., Kahneman, D., 1981. The framing of decisions and the psychology of choice. Science 211 (4481), 453-458.

Tversky, A., Kahneman, D., 1986. Rational choice and the framing of decisions. J. Bus. S251-S278.

Walsh, K.C., 2004. Talking About Politics: Informal Groups and Social Identity in American Life. University of Chicago Press.

Zumbrunnen, J., Gangl, A., 2008. Conflict, fusion, or coexistence? The complexity of contemporary American conservatism. Polit. Behav. 30 (2), 199-221. 